\title{
ESTIMATES OF THE SEVERITY OF COVID-19: A COMPARISON OF PAKISTAN WITH OTHER DEVELOPED COUNTRIES
}

\author{
Yasir Mehmood ${ }^{a}$, Zafar Latif Awan ${ }^{\mathrm{b}}$, Adnan Afzal ${ }^{ }$, Muhammad Saleem Akhtar ${ }^{\mathrm{c}}$, Fawad Hussain ${ }^{\mathrm{d}}$, Muhammad \\ Imran Ashraf ${ }^{\mathrm{e}}$, Hammad Yousaf ${ }^{\mathrm{a}}$ \\ a Department of Pharmaceutics, Faculty of Pharmaceutical Sciences, Government College University \\ Faisalabad, Pakistan. \\ ${ }^{b}$ Department of Community Medicine, Rai Medical College Sargodha, Pakistan. \\ 'Department of Medicine, Rai Medical College Sargodha, Pakistan. \\ ${ }^{\mathrm{d}}$ Department of Community Medicine, Niazi Medical \& Dental College Sargodha, Pakistan. \\ eDepartment of Pharmacology, Rai Medical College Sargodha, Pakistan.
}

\begin{abstract}
:
The number of confirmed cases of COVID-affected patients are 1,123,000 and counting, while more than 59,000 corroborated mortalities have occurred around the globe, as depicted by the data gathered through Johns Hopkins University. More than 228,000 people have reportedly recovered from COVID-19 till April $4^{\text {th }}$ 2020. Italy has the second highest deaths of COVID-19 in the world. There is dire need to evaluate the pattern of COVID-19 in Pakistan and to compare it with other developed countries. World Health Organization has developed website to provide latest data in form of new reported cases, mortality and recoveries. In Pakistan, mortality rate was found less than other developed countries and this hypothesis may be wrong that Pakistan neither will nor be effected with virus due to climate conditions.

The presented study had two objectives. The first was to describe the latest situation of COVID-19 in Pakistan and other developed countries. Second objective was to determine the latest situation about mortility rate in Pakistan and other developed countries. Comparative data was sketched and presented in graphs for 5 countries including Pakistan. All the data was obtained from WHO websites and Pakistan government officials websites. Data was collected from Jan-2020 to $4^{\text {th }}$ April2020.
\end{abstract}

KEYWORDS: Pandemic, Countries, Comparison, Mortality, Prevent.

doi: https://doi.org/10.37723/jumdc.v11i2.421

How to cite this:

Mehmood Y, Awan ZL, Afzal A, Akhtar MS, Hussain F, Ashraf MI, Yousaf H. ESTIMATES OF THE SEVERITY OF COVID-19: A COMPARISON OF PAKISTAN WITH OTHER DEVELOPED COUNTRIES. jumdc. $2020 ; 11(2): 43-48$.

doi: https://doi.org/10.37723/jumdc.v11i2.421

This is an Open Access article distributed under the terms of the Creative Commons Attribution License (http://creativecommons.org/licenses/by/4.0), which permits unrestricted use, distribution, and reproduction in any medium, provided the original work is properly cited. 


\section{INTRODUCTION:}

Coronavirus disease, also known widely as COVID-19, occurs commonly through inhalation of a novel severe acute respiratory pathogenic virus that has caused havoc and devastation worldwide unlike anything we have seen in recent times. It is an enveloped, positive single stranded RNA virus which thrives over human as well as wildlife ${ }^{[1]}$. Overall 6 species have been so far isolated and discovered to develop illness among humans. They have been depicted to infect the neurologic, respiratory, enteric and hepatic systems. COVID-19 has high pathogenicity and is severely contagious as depicted by the development of a globally nurtured pandemic.

This outbreak has been fostered during the month of December 2019, by then unidentified clustering of various respiratory illnesses and were initially reported and described from Wuhan City of China ${ }^{[2]}$. As of April 3, 2020, 1114388 confirmed reports of cases and 59142 mortalities attributed to COVID-19, have occurred around the globe ${ }^{[3,4]}$. The outbreak of COVID-19 through China prompted significant worldwide global attention which culminated it into being pronounced a pandemic. Significant mortalities imputed to COVID-19 soon started being reported throughout the globe. The basic reproductive number (R0) of COVID-19 is shown to be greater than RO of the Severe Acute Respiratory Syndrome Coronavirus, commonly referred to as SARS-CoV as well as the Middle East Respiratory Syndrome Coronavirus known frequently as MERS-CoV. COVID-19 usually presents with asymptomatic etiology, which has significant contribution to it being resulted into an epidemic and now a pandemic ${ }^{[5]}$. The epidemic initially surfaced from mainland China, with a geographical focal point being the city of Wuhan, Hubei. The index case of COVID19 outside of China first had a confirmed diagnosis on 13th of January 2020 in the city of Bangkok, Thailand. As of 2nd March 2020, a total of 67 territories were marked outside of mainland China which reported 8565 confirmed patients of COVID-19 along with a mortality count of 132 , as well as significant community outbreak occurring in various countries throughout the globe, which mainly included Iran and Italy while it was adjudged a global

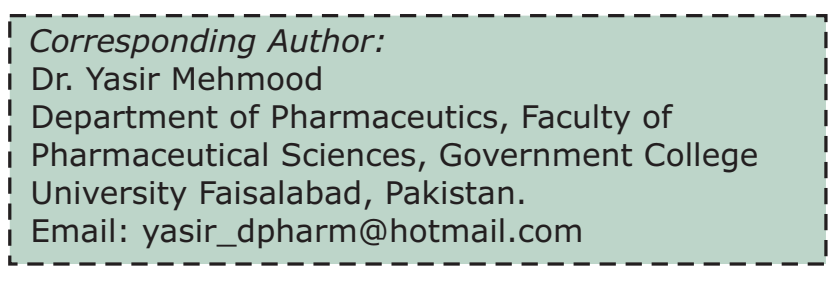

pandemic by WHO on 11th March 2020. The number of confirmed cases is inclining throughout the globe and after surrounding the Asian and European regions, a sharp inclination in cases is currently has caught up the lowincome nations as of $30^{\text {th }}$ March 2020. However, in 2020, the inclining rate of cases turned to be greater throughout the rest of the globe as compared to China. Significant outbreaks surfaced in Italy (119827 cases), USA (277475 cases), Spain (119199 cases), China (81639 cases) as the geographic extensions of the epidemic continues to thrive. The COVID-19 epidemic expounded during the start of December from Wuhan, which is the 7th most populous city of China, exporting from there to a growing number of various countries around the globe. Among Chinese patients 2873 mortalities have occurred which is equivalent to the mortality incidence of 3-6\% while mortality ratio far greater has been reported from outside China. The proportion of serious, severe or lifethreatening infections may also vary from location to location. In concordant with the joint World Health Organization (WHO)-China factfinding commission, the case to case incidence of fatality were graded from $5.8 \%$ in Wuhan to $0.7 \%$ throughout the rest of China. A modeling study suggested that the adjusted case fatality rate in mainland China was 1.4 percent. A high proportion of mortality in various cases was shown to occur in patients with advancing age or who suffered from an underlying medical condition(s) ${ }^{[6]}$. In various parts of Italy, $12 \%$ of all the diagnosed COVID-19 cases as well as $16 \%$ of all the patients who were hospitalized had been treated in the intensive care unit; while the approximated fatality rate of these cases had reached to $7.2 \%$ in the mid of March. However these fatality rates are based due in fact to the number of death rates relative to the confirmed cases of infection which cannot be the representative of the factual death rates. It would be quite daunting to quantitate the precise magnitude of this ongoing pandemic as 
it is essential and logical to count all the reported cases including but not limited to only the serious, severe and symptomatic ones but also the mild ones. However, till date, there has not been any globally logical as well as a defined standard response to the pandemic while every nation faces this ongoing crisis solely based upon their own measurable possibilities, expertise as well as hypotheses. Hence, there have been various different criteria and standards for testing, hospitalization and estimating the cases rendering it daunting to decipher the number and proportion of actual people struck by this epidemic ${ }^{[7]}$. There have been more than $1,123,000$ affirmed reports of infected cases and higher than 59,000 confirmed mortalities throughout the globe, in accordance with the data published by Johns Hopkins University. However, a greater proportion 228,000 cases have reportedly been recuperated from COVID $19^{[8]}$. Within Pakistan, first case was reported On Feb 26, 2020 , and till date there are 44,672 confirmed cases with 12,489 cases recovered and 958 deaths with 15,976 cases in Punjab, 17,947 in Sindh, 2820 in Balochistan, 6,230 in KPK, 1,034 in Islamabad, 550 in $\mathrm{GB}, 115$ in AJK. In Pakistan, mortality rate is $7 \%$. Some people believe that epidemic had surfaced later in Pakistan as compared to the other regions globally, due in part to the limited number of international air traffic, instead of the climate conditions. Earlier detection of unconfirmed cases, swift and rapid contact tracing of individuals affected with physical and social isolation, community engagements and health system steps and measures, all necessitate to the aversion of the potentially deleterious and catastrophic consequences of an epidemic in this region. To draw in on a conclusion, comparisons amongst the confirmed cases in the various countries do not support the speculative hypothesis that COVID-19 will disseminate quite slowly in regions with warmer climates ${ }^{[9]}$. As of 4 April total number of patients within China 81639 as well as outside China 1032749 (whole world) cases for coronavirus disease 2020 (COVID-19). As you know in Pakistan total patients 2708 till 4 April and total 41 deaths ${ }^{[6,10]}$. Amongst the Chinese confirmed COVID-19 patients, 2873 mortalities have occurred, that is equivalent to a mortality rate of $3.6 \%(95 \%$ CI 3.5-3.7), however, 104 deaths related to COVID-19 have been reported outside China $(1 \cdot 5 \%[1 \cdot 2-1 \cdot 7])^{[11]}$.

The incubation period for COVID-19 is believed to be more or less between 14 days following exposure, with a significant proportion of cases taking place roughly between four to five days following exposure. Analyzing a recent study which indulged 1099 patients who had confirmed symptomatic diagnosis of COVID-19, the median incubation period reported was 4 days (interquartile range 2 to 7 days). Analyzing data from 181 publicly accounted and reported, confirmed cases in China with a certainly identifiable and recognizable exposure, one modeling research study estimated that the signs and symptoms would begin to surface in 2.5 percent of infected patients in between 2.2 days and in $97.5 \%$ of infected patients in between 11.5 days. The median incubation period of time in the described research study came out to be 5.1 days ${ }^{[12,13]}$. In this article we had sort out the data from 5 countries (USA, China, Spain, Italy and Pakistan). We had compared the reported case, death rate and recovery rate. In this article we also describe the individual data of Pakistan regarding age, sex and comorbidity.

\section{METHODOLOGY}

We had maintained the data about early deaths from Pakistani officials' websites. We identified and described significant data on the characteristic basis and features of COVID-19 patients who had died in Pakistan. We registered and recorded the following data and information elements, as available: age, sex, date of signs and symptoms onset and date of hospitalization as well as the date of patient death.

\section{DATA ON CASES OUTSIDE OF PAKISTAN}

We had collated data about this disease on April 4, 2020 regarding cases reported in four developed countries, from WHO official websites and media reports. We maintained the following significant data and information as available: country/region in which the case 
were detected and identified more, cases rate, death rate and recovery rate.

\section{DEMOGRAPHICS}

Age-stratified population data for 2020 were gathered from COVID.gov.PK of statistics in Pakistan. According to this data, the population of Pakistan in the year 2020 was approximately estimated to be 197 million people.

\section{STATISTICAL ANALYSIS}

The above data was analyzed using the SPSS version-18. Data were compared by independent sample $t$-tests, and ANOVA was used to compare means. $P$-values $<0.005$ are considered significant.

\section{RESULTS}

\section{COVID-19 CONFIRMED CASES}

The graph (Figure-I) showed total conformed cases in different countries till 4 April. The data has been collected form WHO website. The data showed that Pakistan has very less no of cases than other developed countries. Worst situation presented in Italy and China. In china now study state start but in all other countries cases are increasing day by day. Perhaps more critically, now that COVID-19 has spread to rich, developed regions.

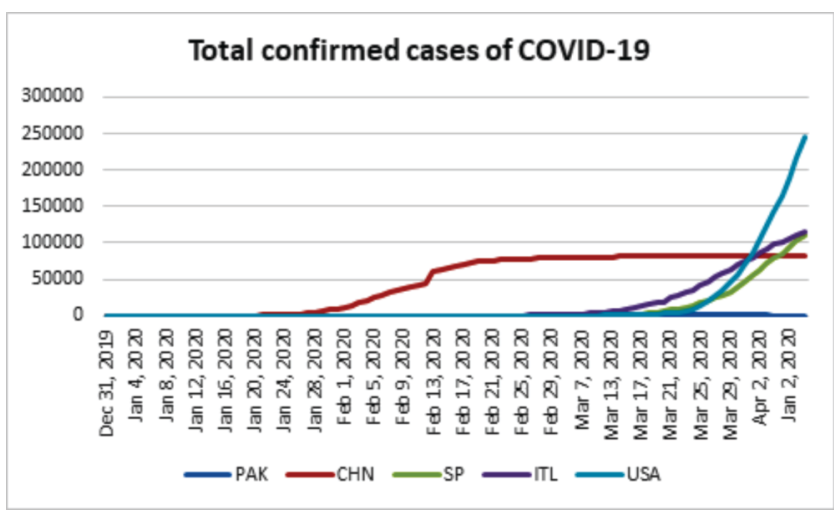

Figure-I: Comparison of total cases (PAK, CHN, SP, ITL and USA)

COVID-19 MORTALITY RATE IN PAKISTAN

$*$ Death Rate $=($ No. of deaths $/$ No. of cases $)=$ Probability of death rate when infected by the virus (\%). The graph (Figure 2) showed total death on Pakistan till 4 April. The data has been collected form Pakistani official website. The data showed that Pakistan has very less no of death than other developed countries. Worst situation presented in Italy and China. In china now study state start but in all other countries cases are increasing day by day. Perhaps more critically, now that COVID-19 has spread to rich, developed regions.

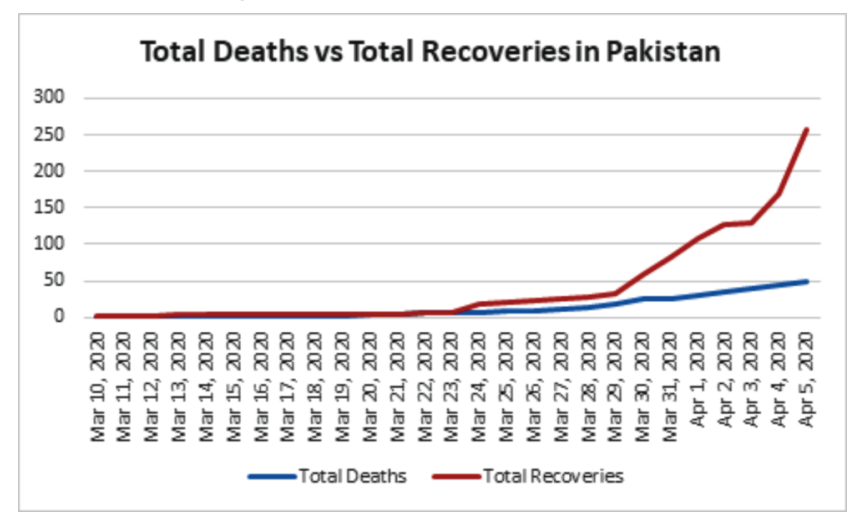

Figure-II: Mortality rate in Pakistan.

The amount of confirmed COVID-19 cases across the globe surpassed $1,123,000$ as of 4 April, according to statistics compiled by the WHO. The pandemic currently spans 175 countries and each inhabited continent. As of 4 April, Pakistan had less number of confirmed cases. The situation in Pakistan is very different from China, Italy, USA and Spain. Currently, Pakistan has more or less 4072 reported confirmed cases, and 50 reported confirmed deaths, although, the researchers claim that infectious cases are probably sieving undetected keeping in context the exact size and proportion of its population. Out of 50 deaths, 14 were reported in Sindh, 13 in Khyber Pakhtunkhwa, 22 in Punjab, three in GilgitBaltistan and one in Balochistan. Punjab remains the most affected province 1,133 confirmed cases, followed by Sindh with 839 cases, Khyber Pakhtunkhwa 372, GilgitBaltistan 194, Balochistan 189, Islamabad Capital Territory 75 and AJK 12 cases. The country has so far recorded 467 confirmed recoveries and total test conducting 30,308, while the deaths and recoveries total 35 and 126, respectively. Under the newly revised restrictions, flights and train transits will remain 
suspended, while road access is restricted within each city of Pakistan. However, medical stores, pharmacies and medical care centers, petrol stations as well as grocery stores have been exempted from the lockdown.

\section{DISCUSSION}

According to the available evidences, the corona virus infection spreads through close contact with infected person, who actually develops disease.The infection does not spread by air rather it spreads through droplets of saliva,sneezing, etc.The people who are at higher risk of getting infection, those are in close contact with hospital admitted patients, care givers. Prevention and mitigation are the key.Most effective and useful measures are includes: If your hands are not dirty on appearance, perform hand hygiene more frequently by rubbing your hands with an alcohol-based hand sanitizer. In case you hands are dirty by appearance, wash them properly with a good hand wash or soap. It is too better to use germicidal hand wash and soap. When you are outside, avoid touching your mouth and eyes with your hands. Practice respiratory hygiene by coughing or sneezing in your bend elbow or in a tissue, then immediately disposed of it. Always wear a medical face mask to cover your nose, mouth and chin properly. Pakistan has started implementing extreme measures and protocols to prevent and/or restrict the spread of the coronavirus. Prime Minister announced lockdown to prevent the pandemic situation in Pakistan. He announced people must restrict and self-isolate themselves while staying home and only stepping outside for extremely important as well as essential tasks and purposes. The police shall have the authority to enforce SOPs along with the rules and regulations while fining people who stray away from such measures and protocols. People shall be allowed to step out of their homes if and only to shop for groceries, essential food items and medical supplies, exercise once a day, as well as travel to work if and only it extremely necessitates. Stores that sell non-essential items shall remain closed while social gatherings of more than two people at once in public places will remain banned. In accordance with UNICEF, in spite of the significant improvements over the last two decades, Pakistan still ranks amongst the bottom of the list of developing countries. Regarding cases of COVID-19 in begging of this year 2020 Pakistan was in controlled situation, but after April in Pakistan cases are significantly increase and WHO has serious concern with Pakistan. WHO demand to Pakistan for strict lockdown in every province. Now a day's total mortality rate in Pakistan is $2.2 \%$ and Pakistan is among the $10^{\text {th }}$ severe countries.

\section{CONCLUSION}

To conclude, ahead of time comparisons amongst the numbers of confirmed cases within the developed nations (USA, Italy, China and Spain) are worst affected countries and Pakistan with confirmed toll of COVID-19 cases does not endorse the hypothesis that the virus will disseminate and spread more slowly within Pakistan and regions having warmer climates. While having a discrete look at the situation in Pakistan, a rapid acceleration in the total number of cases might hastily increase because of our compromises health systems. This has been done in Pakistan after April 2020 and now day situation is worst in Pakistan and need to take more action for safety. Hard and dire actions with essential needy steps to further control the dissemination and spread of the virus while improving the response capabilities of the affected countries like Pakistan is therefore compelling and pressing.

\section{CONFLICT OF INTEREST:}

All authors disclose no conflict of interest.

\section{GRANT SUPPORT \& FINANCIAL DISCLOSURES: None.}

\section{REFERENCES:}

1. Jahan F, Al Maqbali AA. The Middle East Respiratory Syndrome Coronavirus (MERSCOV). World Family Medicine Journal: Incorporating the Middle East Journal of Family Medicine. 2015;99(1645):1. Available from: http://applications. emro.who. int/docs/EMROPub_2018_ EN_20792.pdf?ua=1. 
2. Du Toit A. Outbreak of a novel coronavirus. Nature Reviews Microbiology. 2020;18(3):123-. Doi:10.1038/s41579020-0332-0.

3. Wu Z, McGoogan JM. Characteristics of and important lessons from the coronavirus disease 2019 (COVID-19) outbreak in China: summary of a report of 72314 cases from the Chinese Center for Disease Control and Prevention. Jama. 2020 ;323(13):1239-1242. Doi:10.1001/ jama.2020.2648.

4. Organization WH. Coronavirus disease 2019 (COVID-19): situation report, 67. 2020.

5. Wu C, Chen X, Cai Y, Zhou X, Xu S, Huang H, et al. Risk factors associated with acute respiratory distress syndrome and death in patients with coronavirus disease 2019 pneumonia in Wuhan, China. JAMA internal medicine.2020;180(7):934-943. Doi:10.1001/jamainternmed.2020.0994.

6. WHO(2020)coronavirusdisease2019 (COVID-19). Situation Report-140. https://www. who.int/docs/defaultsource/coronaviruse/situationreports/20200608-covid-19-sitrepth140.pdf?sfvrsn=2f310900_2. [Accessed 8June, 2020].

7. Roser M, Ritchie H, Ortiz-Ospina E, Hasell J. Coronavirus disease (COVID 19)-Statistics and research. Our World in data. 2020.

8. Bedford J, Enria D, Giesecke J, Heymann DL, Ihekweazu C, Kobinger G, et al. COVID19: towards controlling of a pandemic. The Lancet. 2020;395(10229):1015-1018. PMCID : PMC7270596 D o i : 10.1016/S0140-6736(20)30673-5.

9. Wang J, Zhou M, Liu F. Exploring the reasons for healthcare workers infected with novel coronavirus disease 2019 (COVID-19) in China. Journal of Hospital I $\mathrm{nfection}$. 2020 . Doi:10.1016/j.jhin.2020.03.002

10. Raza, S.; Rasheed, M.A.; Rashid, M.K. Transmission Potential and Severity of COVID-19 in Pakistan. 2020, 2020040004. Doi: 10.20944/preprints202004.0004.v1.
11. Surveillances V. The epidemiological characteristics of an outbreak of 2019 novel coronavirus diseases (COVID-19)-China, 2020. China CDC Weekly. 2020;2(8):113122.

12. Lauer SA, Grantz KH, Bi Q, Jones FK, Zheng $\mathrm{Q}$, Meredith $\mathrm{HR}$, et al. The incubation period of coronavirus disease 2019 (COVID-19) from publicly reported confirmed cases: estimation and application. Annals of internal medicine. 2020;172(9):577-82. Doi: 10.7326/M20-0504.

13. Sohrabi C, Alsafi Z, O'Neill N, Khan M, Kerwan A, Al-Jabir A, et al. World Health Organization declares global emergency: A review of the 2019 novel coronavirus (COVID-19). International Journal of Surgery. 2020;76: 71-76. Doi: 10.1016/j.ijsu.2020.02.034 PMID: 32112977

\section{Authors' Contribution:}

Yasir Mehmood: Substantial contributions to the conception or design of the work or the acquisition, analysis, or interpretation of data for the work.

Adnan Afzal: Final approval of the version to be published.

Zafar Latif Awan: Final approval of the version to be published.

Muhammad Saleem Akhtar: Help in data collection analysis and final draft of study.

Fawad Hussain: Drafting the work or revising it critically for important intellectual content.

Muhammad Imran Ashraf: Drafting the work or revising it critically for important intellectual content.

Hammad Yousaf: Help in data collection analysis and final draft of study.

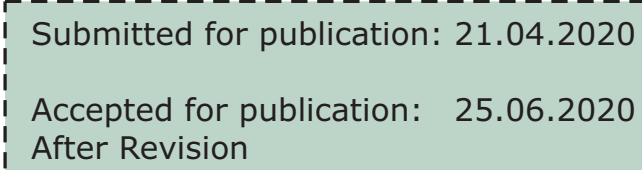

